\title{
Rationality and Foolishness: Alternative Forecasting Systems in a Manufacturing Firm
}

\author{
Charlotte Brown \\ Lancaster University Management School, Lancaster, UK LA4 4YX \\ c. brown1@lancaster.ac.uk
}

\begin{abstract}
Forecasters in firms are expected to employ mathematical techniques encoded in information systems in order to predict the future demand for a firm's goods. In practice, many forecasters have eschewed statistical methods of forecasting and depend instead on human expertise. This resistance to the ideals and technologies of forecasting has largely been understood in the literature as a failure of rationality in firms. This paper provides a social and political analysis of forecasting in a case study firm, and examines alternative rationalities present in the firm that legitimate what appears to the forecasting literature as foolish practices. The case study organization, a large manufacturing firm, undertook a process of reform of the forecasting process during the course of the study. This paper explores how resistance to a new forecasting support system was shaped by the local equilibrium that had been reached between rationalities in the firm.
\end{abstract}

Keywords: Forecasting, organizations, rationality, forecasting support systems.

\section{Introduction}

Foolishness and rational choice exist side by side in every organization. It is easy to theorize about one while ignoring the other. The challenge is to reconcile them (Freeman 1999, p. 164).

When manufacturing firms think about the future, they do so not only on the grand, sweeping scale of product or market (r)evolution, led by CEOs, strategists or consultants; they also think about the future in a much more pragmatic and short term way. These short-term predictions relate to the demand for their goods and/or services from customers in the immediate future: in the next week, month, or quarter. The employees responsible for this task are often known as forecasters or demand planners, and they typically work within the supply chain department or sales, or in a separate department with links to both functions (Fildes and Hastings 1994). The job of forecasters is to gather information about the past (usually the sales history), about the present (market conditions), and about the future (anticipated promotions or seasonal changes) and synthesize these, often using a specialist information system, into a description of the quantity the firm could sell of each product in the future. This is then put to use by a variety of organizational actors: manufacturing departments use it 
to determine what to produce and when; sales departments may use it to set targets; senior managers may use it to make decisions about resource allocation (Makridakis et al. 1998).

Research into forecasting assumes, mostly tacitly, that organizations are rational, profit-maximizing organizations. Better forecasts are expected ultimately to reduce costs and increase revenue by informing decision-making about, for example, optimal production scheduling and inventory management. However, predicting the future, even this relatively near-term and pragmatic aspect of the future, is a notoriously difficult task, made more so by the volume of data that has become available to the forecaster in recent decades. Researchers have, therefore, sought systematic answers to this problem, narrowing attention to the complex but mathematically tractable problem of extrapolating potential futures from trends in historical data (Whitley 1984). They have accordingly developed and elaborated a set of techniques intended to assist the forecaster that are increasingly encoded in specialist forecasting support systems (FSS). Firms are thought to be motivated to purchase and implement these forecasting support systems by the potential for cost savings (Armstrong 2001).

Successful implementation of the technologies of forecasting is thus positioned within the literature on forecasting as a rational choice that precedes good forecasting, and thus good business decisions, and thus profit maximization. However, surveys reveal a rather different picture of forecasting support systems in use (McCarthy et al. 2006; Mentzer and Cox 1984; Mentzer and Kahn 1995). The uptake of forecasting support systems has, it seems, been relatively slow, despite the availability of computing resources in the workplace (Sanders and Manrodt 1994, 2003). Moreover, these surveys suggest that many firms continue to use primarily human-expertisebased approaches to forecasting. They prefer to rely on individuals within the firm, often sales and marketing personnel, to provide opinions about the future that are then used as the basis for forecasts. Even those firms that do use more information technology often seem to do so in ways unintended by the technology developers. They often ignore or misuse the many embedded mathematical techniques that forecasting researchers and experts would consider to be cornerstones of effective practice. This divergence of practice from theory is highly frustrating to forecasting researchers, who are unable to explain this seemingly foolish antagonism of organizations to the proper use of the technologies of forecasting (Mahmoud et al. 1992).

This paper will draw upon a case study of a manufacturing firm in the fast moving consumer goods market to attempt to unpick and reconcile the "rational" and "foolish" choices of a firm that implemented a forecasting system. It will explore how changing ideas of what constituted a successful forecasting practice impacted upon the firm and disrupted forecasting processes.

At the start of the study, the firm maintained two distinct forecasting practices, each very different in approach to the problem of predicting the future. One adhered closely to statistical notions of "good forecasting" while the other was almost wholly deviant from it. We will suggest that forecasters in the case study organization were caught in organizational circumstances that created a very different view on the most rational way to produce forecasts, and their use (or failure to use) quantitative technologies in their forecasting information systems reflected these different rationalities. The paper will then consider how forecasting practices, and thus the balance between rationalities, were then disrupted by the forced introduction of a new forecasting 
support system by senior managers intent upon imposing a single rational system on the whole firm.

This case study will be laid out in more detail in the third of four further sections below. First, however, this paper will briefly review the literature on forecasting in organizations and relate this to ideas of success and failure within the IS literature. The second section will consist of a short discussion of the methodology used to generate the case study. The third section will introduce and discuss the case study firm, a large alcoholic beverages firm that will be described under the pseudonym of Global Beverages UK. Finally, the paper will reach some conclusions about the problem of the rational in forecasting practice, and consider some future extensions of this research.

\section{Literature Review}

\subsection{The Rational Ideal in the Forecasting Literature}

The success or failure of systems is a major theme in the information systems literature. This manifests itself particularly in analyses that locate an IS failure within an organization and then attempt to unravel its origins. This research historically originated in discussions of mechanical deficiencies (Lyytinen 1987), but has increasingly focused on issues not of simple failure to function, but rather of mismanagement, misuse, and abandonment (Wilson and Howcroft 2002).

Epistemologically, two approaches have emerged within this debate, the first of which attempts to isolate the factors that predict and/or permit success. This literature has developed normative descriptions of idealized development and implementtation processes, and proposes multiple tools and techniques to mitigate the risk of failure (DeLone and McLean 1992, 2003). Research of this type suggests that methods can be found to identify, manage, and/or avoid potentially failure-inducing issues related to the organization, human participants, and the organizational culture in which the technology is to operate (Mitev 2000). Much of the existing forecasting literature falls within this category, where success is defined as the implementation and diffusion of the "rational ideal" of the quantitative forecasting system.

Even the most cursory inspection of the academic literature on forecasting reveals a discipline deeply rooted in the science of statistics. The dominant research topic in this field is the development, elaboration, and testing of the technologies of forecasting. This research has produced a set of statistical models and algorithms intended to extrapolate a description of the future from information about the past. The limited capacity of humans for this type of analysis has led to a strong interest in embedding these techniques within forecasting support systems (Hogarth and Makridakis 1981). One of the central concerns of this work is the measurement of statistical accuracy, or the correspondence between the forecast and the actual data for a given period. Much of the forecasting literature assumes straightforwardly that the success of a forecasting process in practice is synonymous with and proportional to the statistical accuracy of the forecast that is produced, with one or two notable exceptions (Lawrence et al. 2000).

A strand of the forecasting literature has explicitly dealt with the problem of forecasting in organizations. This literature is generally highly sympathetic to the 
outcomes of those studies done in laboratories that suggest that the systematic application of forecasting techniques and technologies, combined with carefully controlled integration of human-expertise, produces the best, which is to say the most statistically accurate, forecasts (Armstrong 2001). Legitimacy is expected to accrue to the forecasting support system and its outputs from the rigor of the underlying mathematics and the integrity of the flow of data to and from the system. The organization itself is broadly understood as a more or less hostile host for this technology. Success, therefore, depends in part on the willingness that the organization evinces to change to accommodate the needs of the new technology and to accord authority to the outputs of the new, more accurate system (Moon et al. 2003).

The neutrality of the forecasting system is never called into question in this literature. Indeed, an unexamined teleology of forecasting practices is tacit in much of this work. These works envisage forecasting practices as moving toward greater accuracy, and thus greater success, through the gradual replacement of the human and judgmental with the systematic and mathematical. As a consequence of this, much of this literature is normative. It seeks to outline the organizational arrangements that best support the successful integration of this machinery of forecasting into the firm. For example, these models of "best practice" call for specific efforts to develop systems of communication and data gathering (Fildes and Hastings 1994); suggest that specialist forecasters be employed to operate forecasting systems and be provided with a position in the organizational hierarchy that provides them with political capital (Moon et al. 2003); and demand the creation of a set of policies and rules in the organization that discourage and stigmatize unnecessary human intervention in forecast outputs (Galbraith and Merrill 1996). More critical viewpoints query whether the particular organizational "improvements" that are proposed have ever been shown empirically proven to improve forecasts, let alone produce the better business decisions that are thought to flow from them (Fildes et al. 2003). However, the notion of a need for improvements of some kind is largely unexamined.

One response to the problem of the inconveniently flawed organization has been to suggest that if organizations are unable or unwilling to mold themselves into good hosts for forecasting systems, the software should be used to impose good policy (Fildes et al. 2006). At a minimum, for example, this ideal of rational forecasting practice requires interested non-forecasters to recognize significant limits to their expertise and to accord authority to the analytical systems that have replaced them. As human judgment "adjustments" are often used to modify statistical forecasts unscientifically and to the detriment of accuracy, it has been suggested that forecasting support systems limit and warn against such adjustments, or even "correct" them as they are made (Davydenko et al. 2010).

This literature, therefore, positions quantitative forecasting methods, and the systems they are embedded within, as the rational choice for resolving the problem of predicting the future. Once implemented in firms, the focus shifts to defending these technologies from the distortions and subversions that arise out of the imperfections of the particular firm. It is assumed that the foolishness these imperfections create can and should be designed away, or at least mitigated, either through direct intervention in organizational design and/or policy or else through the design of the technology itself. 


\subsection{The Forecaster as Systems Expert}

This description of the design and implementation of forecasting technologies is strongly reminiscent of Hirschheim and Klein's (1989) description of "the analyst as systems expert," with the same fundamental assumption that the primary concern of the forecaster is the means of production, rather than the end product itself. Forecasters, like Hirschheim and Klein's information systems developers, are expected to concern themselves first and foremost with the task of choosing and applying techniques and models that produce authoritative, accurate forecasting outputs. The extraction of meaning from these forecasts is assumed to be the province of non-forecasters, usually sales and production employees who take decisions based on their interpretation of the information. Much of the frustration expressed in the forecasting literature concerns the vitiation of the methods of production of forecasts by non-forecasters and/or the reluctance of non-forecasters to cede authority for describing the future to the forecasting system.

Kling (1980) describes analysis of this type as a "traditional management-science approach," imagining how forecasting systems would work in an idealized world. Kling further suggests that it is often followed up by a "human relations" analysis of the same problem which encourages system designers to consider this problem of resistance productively. Kling describes this as a belief that a technical solution can be found that permits the needs of a number of organizational actors to be met, including both the managers requiring information and the various contributors to the system. This manifests itself in the forecasting literature in the various recommenddations on how to realize the perfect world of forecasting practice by reform of the organization.

\subsection{The Analyst as Facilitator}

An alternative perspective of the activities of forecasters within the firm, however, is one consistent with Hirschheim and Klein's notion of the "analyst as facilitator." This attempts to understand the forecast not simply as the output of an objective information process that is strictly geared toward producing the forecast, but rather focuses on the method of this production as a meaningful activity in itself. This approach is useful because it allows us to understand differences between theory and practice as more than delinquency. Instead they can be understood as indicative of some meaningful need or desire of participants in the firm. This stance takes the less critical position that forecasting systems develop in an organization in a particular form because this provides the greatest utility to one or more organizational actors. Consequently, we are no longer constrained to treat organizational arrangements as either rational or foolish, but rather to explore and investigate them as the effects of particular organizational attitudes and processes. In this approach we leave it to organizational participants to determine who extracts meaning from forecasts and how they do so, and what measure of success might be applied to these activities. In particular, it suggests that the disinterested, objective measurement of statistical accuracy may be only one measure of success relevant to forecasters and forecast users. 
This position is consistent with a second thread of the information systems success/failure debate, which argues that normative and instrumental approaches to understanding the failure of information systems rely on a faulty assumption that technology is inherently neutral (Mitev 2000). The second type of research, by contrast, broadly identifies with constructivist schools of thought. Success or failure of information systems is understood in this view to be socially constituted. It is determined by the dominant narrative that emerges from organizational participants, irrespective of the extent to which the project conforms to checklists of success (Wilson and Howcroft 2002). This type of analysis, therefore, relies on investigating the relationship between value-laden technological change and patterns of interests and power within the firm. Recent examples include Brown and Jones (1998), who consider narratives of doom that emerged in a failed IS project at a UK hospital; Fincham (2002), who considers the emergence of different dominant success/failure narratives within two financial services firms; and Bartis and Mitev (2008), who discussed the impact of managers "disguising" a failure as a success in order to save face or secure power in a case study firm.

In this paper, the intention is to apply these ideas to a single case study as an example of this approach. It aims to examine how rationality, so clear cut in the mathematical approaches to forecasting, is in fact contingent upon the firm and the socio-political processes that surround the initiation, processing, outcome, and interpretation of forecasts. In this view, behaviors and outcomes from a forecasting system, which might appear foolish under functionalist viewpoints, can be construed alternatively as rational. We are also able to explore how an established practice was recast from successful to failing by means of the interpolation of a technology controlled and promoted by a group with particular organizational power. Before describing this case in detail, however, the next section will briefly outline the methodology used to generate data about the firm in question.

\section{Methodology}

This investigation into the problem of forecasting practice sought to explore the experiences and behavior of forecasters within an organizational context. This study, therefore, took an interpretive case study approach (Walsham 1995). The firm chosen for this case study was a large multinational manufacturing firm that produces alcoholic beverages. The firm was considered to be a useful example of forecasting practice as it has a relatively stable and well-documented forecasting process. Data was generated from 2008 to 2010 through a set of 15 semi-structured interviews with two forecast managers and two senior forecasters at the UK headquarters of the firm, as well as two non-forecasters: a supply manager and an inventory manager. Interviews were conducted primarily with a single interviewee, with one extended interview involving both forecasting managers, and typically lasted between one and one and a half hours. The interview guide consisted of a set of queries intended to elicit details about the day to day creation, revision, dissemination, and review of forecasts in the firm. Forecasters, for example, were asked to describe their routine interacttions with forecast inputs and outputs, forecast users and other data related to forecasts, as 
well as their use of the forecasting support system. Forecast managers were asked questions that related to these issues, and to issues surrounding the measurement and perception of forecasts and forecasters in the firm. All but one of the interviews was recorded, transcribed, and the transcripts, or notes in the case of the one unrecorded interview, were shared with the interviewees for further clarification and checking. Additionally, the organization supplied internal documents related to forecasting outcomes, processes, and hierarchies within the firm.

It is also useful to consider the role of the researcher in conducting this research. This case study forms part of ongoing research undertaken as part of my doctoral studies. Prior to undertaking this research I worked in a firm in a different industry that was nevertheless experiencing some similar challenges in terms of the implementation and use of forecasting techniques. In the course of interviews at the case study firm, I disclosed my previous work experience, and this revelation of my own history may have affected their description of practice in particular ways unknown to me, or to have influenced their choice of terminology or the topics, within the bounds of the semi-structured nature of the interviews, that they chose to discuss. As with all interpretive cases, I must note the contingent nature of this description, which is necessarily constructed in ways consistent with my understanding of the world, both tacit and explicit.

With these caveats, in the next section the forecasting practices of the case study firm, which will be called Global Beverages UK, will be described in detail, followed by analysis and discussion of the case in order to explore the issues raised in earlier sections of this paper.

\section{Case Study}

\subsection{An Introduction to Global Beverages $\mathbf{U K}^{1}$}

Global Beverages UK is the British subsidiary of a global alcoholic beverage manufacturer and distributor. The parent organization, Global Beverages Worldwide, operates in most parts of the world where alcoholic beverages are consumed. At the time of the study, the Global Beverages Worldwide parent company was divided for managerial purposes into several geographic groups known internally as business units, each of which had a regional headquarters site and employed a number of employees dedicated to certain centralized functions as well as senior managers responsible for the entire region. Global Beverages UK was part of the European Business Unit (EBU), which had physical headquarters in mainland Europe and was responsible for operations throughout the European Union and Scandinavia, although the UK, France, and Germany were the largest markets. The UK market for Global Beverages' goods was fiercely competitive, made more so by a long-term decline in sales volumes and a gradual erosion of profit margins. In response to these trends, Global Beverages UK was focused on reducing costs to maintain profitability in shrinking sectors.

\footnotetext{
${ }^{1}$ Names and some minor identifying details have been changed to preserve the anonymity of participants.
} 
Historically, the managerial oversight provided by the EBU in national markets was fairly limited, with major markets like the UK permitted considerable control over their own operations. Over the period from about 2005 to 2010, however, a series of cost saving programs were initiated by supply chain managers at the EBU with the aim of eliminating or at least reducing duplication of activities between the various national organizations. These functions were in some cases consolidated into a multinational team based in the EBU headquarters or else, most recently, to a new service center based in a lower labor cost country in Eastern Europe. Although several related supply chain functions were affected by these changes, responsibility for demand planning had, for the time being, remained with the local Global Beverages organization. However, EBU supply chain managers were increasingly interested in forecasting outcomes and intervened regularly in processes, metrics, and systems related to forecasting. This included an EBU-initiated project to review and streamline forecasting in the UK under the aegis of a well-known management consultancy firm. A particularly critical element of these interventions was a series of redefinitions within the firm of the meaning of "success" as it related to both forecasting practice and forecasting outcomes.

\subsection{Forecasting at Global Beverages UK}

At the time of the study, forecasters in Global Beverages were split into two teams, each serving a distinct customer group which represented approximately half the total revenue of the firm. Each team consisted of a number of forecasters and a forecasting manager with overall responsibility for the forecasts and the team. The two customer segments were known as (1) the licensed trade and (2) the at-home or retail trade. These segments differed very significantly in both customer profile and their treatment by the firm for forecasting purposes.

\subsubsection{The Licensed Trade}

The licensed trade consisted of sales to business premises where customers consumed beverages on site. In the UK, this sector included a large pub, bar, and club trade, as well as licenses held by, for example, the operators of large sporting stadia. While there were some large accounts in the licensed trade, no single customer was felt to be critical to the on-going success of this side of the business.

The licensed trade was seasonal, with spikes and troughs in demand related to major sporting events (such as the football World Cup) and calendar events. However, there was little significant promotional activity in this segment, and much of the seasonal variation could be foreseen months ahead based on historical sales patterns. Moreover, a relatively small number of stock-keeping units (SKUs), at most two dozen, accounted for the vast majority of sales to all licensed trade customers nationwide, including promotional sales. These factors together produced a relatively stable and predictable demand pattern. From a forecasting perspective, this was seen as an ideal situation in which to use statistical forecasting techniques and the forecasters, therefore, employed a software package to produce forecasts. These were reviewed only by exception or when specific information was provided to them (for example, 
about a forthcoming promotion). Forecasters in this department consistently produced the most accurate forecasts of any in the EBU countries throughout the period of the study, and were considered to be the "best practice" forecasting department in the EBU and beyond.

\subsubsection{The At-Home Trade}

The at-home trade consisted of sales to premises where customers purchased beverages to consume at home. This was further divided, organizationally, into (1) wholesale accounts that purchased in bulk and then resold goods to smaller retail outlets and (2) multi-store retailers, notably three to four large and fiercely competitive national supermarket chains. This latter group was by far the most significant set of customers in the at-home trade side of the business. One retailer in particular, a very large multi-store grocer, was identified as business critical. Meeting the demand from this customer was, therefore, an organizational priority, even if doing so resulted in disappointing other customers.

At the total volume level (i.e., the total number of liters of product, however packaged), sales of most brands were reasonably predictable in this channel, with seasonal and event driven spikes and troughs that were not dissimilar to those observed in the licensed trade. However, at the level of the physical product, demand in the at-home trade was chaotic, with multiple packaging types producing hundreds of different SKUs, some of them customer and/or promotion specific. In addition, forecasters had to factor in several SKU-specific promotions every month, both major and minor, many agreed with retailers in the same month or even week that they occurred. The dynamics of the competitive multi-store grocer market made the outcome of these promotions particularly difficult to predict. At the SKU level, therefore, historical data was thought to provide little clue to future demand for particular package types and sizes. The department had consequently come to rely heavily on judgmental, which is to say human-expertise-based, methods of forecasting. The basis of forecasts for these products was a set of views collected from sales and marketing personnel about their sales and promotion expectations for the next several months.

The Global Beverages UK at-home team had the worst forecasting accuracy in the EBU throughout the period of the study, much worse than comparably sized at-home markets in France and Germany. This produced additional costs for manufacturing and supply planning departments, and occasionally led to difficult customer service situations when demand could not be met from Global Beverages' inventory. Historically, however, the at-home team were also understood to be highly successful. Despite their relatively poor forecasting accuracy, market conditions were such that tolerance for error was much greater, and the ability of forecasters to negotiate between the needs of the production departments and sales teams at the mercy of demanding retail customers was held in high esteem.

However, during the course of this study, the definition of what it meant to be a successful at-home forecaster at Global Beverages UK changed. Senior EBU supply chain managers were keen to improve forecasting accuracy to something closer to that achieved in France and Germany, if not to the level of the UK licensed trade segment. Additionally, the means of production of forecasts became more important. Part of a review of the UK forecasting process in 2010 was intended to determine how to 
implement the statistical forecasting techniques in the at-home trade, despite previous failures at this task and the opposition of both the forecasting managers and UK sales managers.

\subsection{Change at Global Beverages}

During the course of the study at Global Beverages, the EBU stepped up the pace of a long-standing project of integration and harmonization of supply chain processes across the member countries. The forecasting function was affected by multiple rounds of reform over the course of the study. In 2008, the FSS that the licensed trade team had used for many years was abandoned in favor of a single software platform, SAP APO. This was to be used by all forecasters in EBU countries and integrated with the enterprise resource planning software already in use in production departments, although by 2010 only the UK had completed the transition. In 2010, a major consulting project undertaken at the behest of supply chain managers at the EBU examined forecasting processes in several of the major markets. This project determined that too few products were forecast using statistical techniques in the UK. This latter project coincided with the departure from the firm of the at-home forecasting manager and one further forecaster, who were made redundant in a related cost-saving program. This removed a major obstacle to statistical forecasting in the at-home division. The forecasting manager had been vehement in his rejection of these methods for his department and had previously worked with the licensed premises forecasting manager and senior sales managers in the UK to preserve the status quo.

These reforms produced little change for forecasters in the licensed premises team. However, forecasters in the at-home market side of the business were told that henceforth a majority of forecasts were to be completed first in the FSS, which used statistical models, and then adjusted for managerial information such as promotions. The aim was, therefore, to move away from a situation in which human experts forecast half the revenue and more than 80 percent of all SKUs qualitatively, to a new regime in which no more than 20 to 25 percent of SKUs would be forecast manually and the remainder would be produced statistically. The level of accuracy that was acceptable was also reset at a significantly higher level.

Forecasters were skeptical about the change in methods and reluctant to abandon previous ways of working in the at-home segment. It was argued that because of the volatility created by promotional activities, most SKUs could not be forecast with any more success using statistical methods than they had been using human judgment, and in many cases these forecasts were actually worse than the forecasts produced using judgment. However, as new measures introduced by the EBU now reviewed not only the accuracy of forecasts, but also the way in which they were produced, forecasters had no option but to acquiesce. In the short-term, forecasters were committed to a course of action that involved producing both judgmental and system forecasts and choosing whichever seemed more plausible given sales histories. Although forecasters were, as required, now disseminating forecasts from within the mandated software, a line in the forecasting software had been enabled that allowed forecasters to overwrite the "system forecast" with a "manual" alternative, which they produced judgmentally in the same manner they had always done. 


\section{Discussion}

The striking thing about the Global Beverages UK example was that there were two forecasting practices operational within the same firm that used diametrically opposed forecasting techniques, and which experienced wildly different accuracy outcomes. It is even more remarkable that despite the disparity in the accuracy of outputs, managers in these teams saw no contradiction in the coexistence of these practices. It was not until new narratives, backed by the organizational power of the regional headquarters, began to emerge about what constituted successful, legitimate forecasting processes that this status quo was called into question.

\subsection{The Functionalist Perspective on Global Beverages}

Forecasters throughout the organization described themselves as being squeezed between cost-minimizing supply chain managers and revenue-maximizing sales directors, their role one of go-between, translator, and whipping boy all at once. Forecasters in both departments thought of their role as providing a neutral middle ground between these two sets of interests, with one forecasting manager remarking that he thought only forecasters had any sense of the organization's over-arching desire for profit maximization, rather than one or another of the components of this goal. This is consistent with many of the descriptions in the functionalist literature that emphasizes the importance of objectivity. This functionalist position appeared to triumph in Global Beverages, as EBU managers mandated the harmonization of forecasting practices, arguing that the reasons provided by the at-home forecasters for their deviation from these methods were no longer sufficient to explain the failure to use statistical techniques. From the forecasting research perspective, this change at Global Beverages represents a natural, rational evolution of forecasting practice toward a desirable end. The decision of forecasters to circumvent the system in the early stages of deployment appears both baffling and foolish.

\subsection{A Facilitative Interpretation of Global Beverages}

Examining this situation from a different perspective, however, it is useful to consider how information technologies in use in the two forecasting practices reflect a perception of rational choice within the department, irrespective of the dysfunction this may have created in outputs.

In the licensed premises segment, demand was relatively stable, predictable, and involved a relatively small number of products. There were many low-volume customers, and a combination of the market strategy these customers pursued and national regulations on the sale of alcohol inhibited promotions. There were additionally some barriers for customers who wanted to switch between vendors in the licensed premises trade that further discouraged volatility. Relationships with customers were consequently relatively long-term and slow to change. Although the sector was still competitive, forecasting in this segment of the market was relatively undemanding. Forecasters described the data sets as regular and predictable, and the decision to use quantitative techniques was described as has having followed the determination that the data set supported their use. 
Even in this department, with a pattern of respectable, technical forecasting, forecasters were passionate about the development of credible forecasts, and about the importance of personal relationships with contributors to forecasts, forecast users, and even with the data itself in producing credible forecasts. Despite their emphasis on the importance of their role as the neutral information broker between supply chain and sales, in this department, forecasters viewed their role as more strongly oriented toward the needs of the production department, and therefore closely aligned with the cost-minimizing inventory, efficiency, and planning goals of manufacturing managers.

In the at-home trade, by contrast, the scenario with regard to customer relationships was much more complex. A small number of customers exerted enormous influence over the visibility and availability of Global Beverages' products to end consumers. Switching costs for the retailer were relatively low, particularly since there were two or three highly competitive firms offering similar and, it was felt, increasingly commoditized products in most categories. The retailers, moreover, were themselves thought to be positioning their resources to be highly responsive to the end-consumers they served. They demanded a supply relationship that would permit rapid responses to small changes in demand arising from weather changes, competitive dynamics, and the like.

Against this background of an extremely dynamic customer base who perceived their needs to change on a weekly, if not daily, basis, sales people working in Global Beverages were equally active and responsive. The comfortable certainty of business in the licensed trade sector was absent, and instead sales people were described as under constant pressure to maintain and increase sales to a small number of demanding and capricious customers. There was a sense among forecasters that failure to meet those demands would result in not only the loss of that volume to a competitor, but also a damaging black mark against the business that would result in the loss of future sales. Forecasters, therefore, understood their role as sales focused and revenue-maximizing, rather than cost-minimizing. The perceived chaotic nature of the historical data had resulted in disinclination toward quantitative techniques. Perhaps more importantly, however, the sense that individual sales people, or at least the customers they represented, could make or break the revenue expectations of the division resulted in a significant reliance on their qualitative expertise. The appeal of the objective measure of accuracy was much lower than more subjective measurements of customer satisfaction and willingness to purchase.

In this customer-led environment, therefore, formal statistical methods were understood as an intrusion upon the agency and importance of the salesperson and his or her people skills. Consequently, the forecaster had become a collector rather than a producer of information, a historian of sales information. The authority of the forecast derived from the ability of the forecaster to render many narratives about the future into a single, credible narrative consistent with the past.

\subsection{The Impact of Disruptions to Practice}

The position taken by the forecasters, therefore, that the separation of their function into two distinct pieces was adapted to the needs of the organization was then disrupted by the change in the definition of successful forecasting that occurred. The 
investigations of the consultancy firm into forecasting at Global Beverages UK produced, without any particular investigation of the data set, the recommendation that the firm should achieve cost savings by forecasting more SKUs using quantitative methods within an FSS. It was too early at the conclusion of the research project to determine the accuracy of this statement, although forecasters at the firm initially claimed that it was not the case. However, it is interesting to consider the motivation of EBU managers in mandating this change.

It seems unlikely that an ideological commitment to statistical forecasting was strongly felt among supply chain managers at the EBU. A forecasting manager noted instead that the drive toward quantitative forecasting appeared to arise at least partly from a desire for systems integration among member countries. More cynically, the forecasting manager also expressed a belief that that a revolution in forecasting practice that forced the at-home practice onto the same technical footing as other groups would permit further cost savings in future. In particular, the manager pointed to the changes in other supply chain functions, where activities were first rationalized, then moved on to a common platform, and then finally moved to a service center in a lower labor cost country in Eastern Europe as an example of how these cost savings might be achieved in later years.

EBU supply chain managers, therefore, seem to have taken the position that expertise in forecasting ought primarily to be of a technical nature, de-emphasizing the idea of the forecaster as a neutral go-between. This position assumed also that the forecast would have a claim to authority and validity as a result of the system from which it originated, a system that EBU managers now controlled. This was in sharp contrast to the expressed belief of all the forecasters that the credibility of their forecasts depended in part upon the long-term relationships they had built with users and the data. The forecasting literature would regard this change in practice as neutral, part of the natural evolution of forecasting processes. However, in Global Beverages, this change was far from neutral; it represented a significant shift in the relative power of the forecasters and the EBU supply chain managers at regional headquarters.

A further demonstration of this issue was observed when EBU managers began to question the role promotions played in the department, challenging the perception that the UK had special market conditions that resulted in the use of promotions. Instead, UK managers were asked whether the use of promotions had created the market conditions they faced. It was suggested that customers could be "retrained" to expect fewer promotions and a more favorable trading environment for Global Beverages. The revenue-maximizing rationale of the sales department is entirely absent from this discourse: EBU managers were in effect asking Global Beverages UK sales people to conduct business in a way that made forecasting easier, and therefore reduced costs.

If forecasters under the original regime felt themselves to be squeezed between the complementary rationales of revenue-maximization and cost-minimization before, these reforms imposed upon them by EBU substantially increased the pressure. In the early stages of the implementation, it is hard to say what equilibrium will eventually be reached. However, even as a classic rational, technical forecasting package was apparently implemented in the at-home trade department, there were unintended consequences: qualitative forecasts were now written into a line in the technical forecast, taken from an unregulated set of spreadsheets put together by forecasters; 
and sales managers had taken steps to shelter forecasters within their own departments, with unknown consequences.

Reflecting back on the forecasting literature, it is easy to understand the frustration of rationalist expert forecasters confronted with this determined delinquency from the rational course of action. Here, the firm has taken one of the necessary steps to reform forecasting practices only to experience resistance and subversion of the new system. The perspective of the forecaster-as-facilitator, however, makes sense of some of these apparently foolish behaviors. What has been rendered in the forecasting literature as resistance to the technology occasioning from ignorance, self-interest, or stubbornness can be understood from this perspective as arising instead from the disruption of a finely balanced equilibrium of interests. The forecasting support system intrudes upon the forecaster's position as mediator between the cost minimizers and revenue maximizers, and upon the salesperson's agency and expertise. It attempts to establish the credibility of forecasts as being obtained through the means of their production, rather than from the process of collecting, sharing, and making sense of this information. Although neither practice is entirely functional, it is clear that at least within the organization what forecasting experts might code as folly appears rational.

\section{Conclusions and Future Research}

The problem of practice in the forecasting literature has typically been presented as a failure by firms to diffuse the technologies of forecasting in a way forecasting experts have deemed adequate. This paper examined forecasting practice from a more social and political perspective, using the example of Global Beverages UK in order to explore how the practices dismissed as foolish by the rationalist approach persist in firms. This discussion of two different forecasting practices within the same firm found that, in each case, forecasters had developed a practice that most effectively mediated between pressures to minimize cost and to maximize revenue in markets of different levels of uncertainty. When a top-down process of reform, intended to diffuse forecasting technologies more widely, was implemented, it produced a conflict between the forecaster's sense of the role salespeople and forecasters played in forecasting processes, and the paradigm of the uninvolved technical forecaster. These conflicts play out in the organization as resistance to and subversion of the rational forecasting support system, but are indicative of the balance that has been struck between rational interests that participants see no alternative but to preserve.

A paper of this length provides little scope to explore further some of the questions raised by this case study. This description of forecasting in a firm raises further questions about the role of information systems in creating and legitimating a view of the future. In Global Beverages, different levels of uncertainty produced various degrees of reliance on human judgment, and the question of how uncertainty affects the use of forecasting support systems bears further investigation. Finally, this is just one case study, and while useful as a description of the conditions that can affect firms, further exploration of this notion of alternative rationalities as they affect forecasting practice in other firms would no doubt be enlightening. 


\section{References}

Armstrong, J.S.: Principles of Forecasting: A Handbook for Researchers and Practitioners. Kluwer Academic, Boston (2001)

Bartis, E., Mitev, N.: A Multiple Narrative Approach to Information Systems Failure: A Successful System That Failed. European Journal of Information Systems 17, 112-124 (2008)

Brown, A.D., Jones, M.R.: Doomed to Failure: Narratives of Inevitability and Conspiracy in a Failed IS Project. Organization Studies 19, 73-88 (1998)

Davydenko, A., Fildes, R., Trapero Arenas, J.: Judgemental Adjustments to Demand Foremcasts: Accuracy Evaluation and Bias Corrrection. Lancaster University Management School Working Paper (2010)

DeLone, W.H., McLean, E.R.: Information Systems Success: The Quest for the Dependent Variable. Information Systems Research 3, 60-95 (1992)

DeLone, W.H., McLean, E.R.: The DeLone and McLean Model of Information Systems Success: A Ten-Year Update. Journal of Management Information Systems 19, 9-30 (2003)

Fildes, R., Bretschneider, S., Collopy, F., Lawrence, M., Stewart, D., Winklhofer, H., Mentzer, J.T., Moon, M.A.: Researching Sales Forecasting Practice: Commentaries and Authors' Response on "Conducting a Sales Forecasting Audit" by M. A. Moon, J. T. Mentzer and C. D. Smith. International Journal of Forecasting 19, 27-42 (2003)

Fildes, R., Goodwin, P., Lawrence, M.: The Design Features of Forecasting Support Systems and Their Effectiveness. Decision Support Systems 42, 351-361 (2006)

Fildes, R., Hastings, R.: The Organization and Improvement of Market Forecasting. The Journal of the Operational Research Society 45, 1-16 (1994)

Fincham, R.: Narratives of Success and Failure in Systems Development. British Journal of Management 13, 1-14 (2002)

Freeman, J.: Efficiency and Rationality in Organizations. Administrative Science Quarterly 44, 163-175 (1999)

Galbraith, C.S., Merrill, G.B.: The Politics of Forecasting: Managing the Truth. California Management Review 38, 29 (1996)

Hirschheim, R., Klein, H.K.: Four Paradigms of Information Systems Development. Communications of the ACM 32, 1199-1216 (1989)

Hogarth, R.M., Makridakis, S.: Forecasting and Planning: An Evaluation. Management Science 27, 115-138 (1981)

Kling, R.: Social Analyses of Computing: Theoretical Perspectives in Recent Empirical Research. Computing Surveys 12, 61-110 (1980)

Lawrence, M., O’Connor, M., Edmundson, B.: A Field Study of Sales Forecasting Accuracy and Processes. European Journal of Operational Research 122, 151-160 (2000)

Lyytinen, K.: Different Perspectives on Computer Systems: Problems and Solutions. ACM Computing Surveys 19, 5-46 (1987)

Mahmoud, E., DeRoeck, R., Brown, R., Rice, G.: Bridging the Gap between Theory and Practice in Forecasting. International Journal of Forecasting 8, 251-267 (1992)

Makridakis, S., Wheelwright, S.C., Hyndman, R.J.: Forecasting: Methods and Applications. Wiley, New York (1998)

McCarthy, T.M., Davis, D.F., Golicic, S.L., Mentzer, J.T.: The Evolution of Sales Forecasting Management: A 20-Year Longitudinal Study of Forecasting Practices. Journal of Forecasting 25, 303-324 (2006)

Mentzer, J.T., Cox, J.E.: Familiarity, Application, and Performance of Sales Forecasting Techniques. Journal of Forecasting 3, 27-36 (1984) 
Mentzer, J.T., Kahn, K.B.: Forecasting Technique Familiarity, Satisfaction, Usage, and Application. Journal of Forecasting 14, 465-476 (1995)

Mitev, N.: Towards Social Constructivist Understandings of IS Success and Failure: Introducing a New Computerized Reservation System. In: Proceedings of the 21st International Conference on Information Systems, Brisbane, Australia, pp. 84-93 (2000)

Moon, M.A., Mentzer, J.T., Smith, C.D.: Conducting a Sales Forecasting Audit. International Journal of Forecasting 19, 5-25 (2003)

Sanders, N.R., Manrodt, K.B.: Forecasting Practices in US Corporations: Survey Results. Interfaces 24, 92-100 (1994)

Sanders, N.R., Manrodt, K.B.: Forecasting Software in Practice: Use, Satisfaction, and Performance. Interfaces 33, 90-93 (2003)

Walsham, G.: Interpretive Case Studies in IS: Nature and Method. European Journal of Information Systems 4, 74-81 (1995)

Whitley, R.: The Fragmented State of Management Studies: Reasons and Consequences. Journal of Management Studies 21, 331-348 (1984)

Wilson, M., Howcroft, D.: Re-conceptualising Failure: Social Shaping Meets IS Research. European Journal of Information Systems 11, 236-250 (2002)

\section{About the Author}

Charlotte Brown is a Ph.D. student in the Department of Management Science at Lancaster University in the UK. Prior to undertaking her Ph.D. studies, Charlotte spent a decade in a variety of roles in blue chip firms, including Johnson \& Johnson and Sun Microsystems. Most recently she worked as a business intelligence analyst reporting at board level on sales and market forecasting. She has a BA (Hons) from Oxford University, an MBA from Cornell University, and an MRes from Lancaster University. 